\title{
Biodiversity and Climate Change
}

Sandrine Maljean-Dubois, CERIC (UMR 7318 CNRS-Aix-Marseille University) ${ }^{1}$

Matthieu Wemaëre, Paris and Brussels Bar Associations, Associate Researcher CERIC (UMR 7318 CNRS-Aix-Marseille University)

\section{- Abstract}

Sustainable development requires understanding both the ecological and socioeconomic dimensions of the interdependence between the climatic system and biodiversity. And coherent and integrated policies and measures should be adopted at all levels to address the critical role of biodiversity. However climate change and biodiversity related issues are addressed in a specific though fragmented manner through two of the three so-called Rio Conventions adopted in 1992, namely the UNFCCC and the CBD.

Firstly, this contribution recaps the way each of these UN treaties address climate change and biodiversity related issues in the light of its own objectives and provisions. Secondly, it looks at the efforts made or not in each regime to strengthen the coordination toward more interconnected policies and measures. Thirdly, it hightlights some current challenges to address the need of a better synergistic approach of these issues.

\section{- Selected keywords}

biodiversity, climate change, conventions, forests, IPCC, IPBES, United Nations, United Nations Framework Convention on Climate Change, Kyoto Protocol, Convention on Biological Diversity, international law

- Detailed table of contents

1. Two compatible treaties

2. COP decisions : building bridges?

2.1 Adressing climate change into the CBD

2.2. Cautious openness to biodiversity in the UNFCCC

3. Some current challenges

3.1. The need to improve further cooperation between the secretariats

3.2. Improving common understanding and cognitive and normative consistency

3.3. Improving regimes consistency through fundings?

3.4. Challenges and future perspectives of the climate Paris agreement Conclusion

\footnotetext{
${ }^{1}$ This work was supported by the French National Researh Agency within the interdisciplinar project CIRCULEX $<$ ANR-12-GLOB-0001-03 CIRCULEX >
} 
Climate change and loss of biodiversity are two major environmental threats at the beginning of the 21 st century and it is now well-admitted that they are closely interconnected.

A changing climate has implications for ecosystems and biodiversity. According to the Millennium Ecosystem Assessment, climate change is to become one of the most severe drivers of biodiversity loss by the end of the century. ${ }^{2}$ This statement is even supported by the IPCC reports. ${ }^{3}$ The negative impacts of climate change increase the pressure put on natural ressources, interfere with natural interactions among ecosystems, threaten genetic diversity and favour the appearance of invasive species. Yet, the majority of models indicate alarming consequences for biodiversity, with the worstcase scenario leading to extinction rates that would qualify as the sixth mass extinction in the history of the earth. ${ }^{4}$

In turn, conserving biodiversity can help mitigate climate change by protecting and enhancing the natural carbon capture and storage capacity of ecosystems ('carbon sinks'). But conserving biodiversity helps also adapt to climate change. Thus "ecosystems with high biological diversity are more resilient to climate change and climate variability than impoverished ecosystems". 5

Forests and soils are exemplative of this complex interplay. From the perspective of climate change, forests are now recognised as both reservoirs and sources of atmospheric carbon dioxide. In particular, tropical deforestation is viewed as a major source, representing 20 to $25 \%$ of global emissions. Actually, tackling the issue of deforestation and degradation of tropical forests can be beneficial for both climate change and biodiversity.

According to the IPCC, climate policy interacts with the conservation of biodiversity creating the possibility of co-benefits or adverse side-effects. These intersections, if wellmanaged, can strengthen the basis for undertaking climate action. Mitigation and adaptation can positively or negatively influence the achievement of other societal goals, such as biodiversity; and vice versa, policies toward biodiversity can influence the achievement of mitigation and adaptation objectives. For the IPCC, "this multi-objective perspective is important in part because it helps to identify areas where support for policies that advance multiple goals will be robust". 6

These interplays complicate clearly the governance of Earth system ${ }^{7}$ and are hardly captured by international law. In fact, despite their ecological interdependence, climate change and biodiversity gave birth to two different and separate regime complexes at the international level: the United Nations Framework Convention on Climate Change (UNFCCC, 1992) and its Kyoto Protocol (1997) on one side and the Convention on biological diversity (CBD, 1992) on the other side. The operation of the latter regime is likely to influence directly the effectiveness of the former. ${ }^{8}$ But linkages between them, and in particular normative interactions, remain so far little explored, in particular from a positive perspective. However, there is a great potential for synergies. Adressing these two major environmental threats lead to the question as to how the regimes could be better co-ordinated in order to avoid conflicts and, on the contrary, maximize such synergies.

When looking at this issue more closely, it seems clear that each of the two regimes have taken the issue differently. Focus on biodiversity has not been a priority of the Parties to the UN Climate Change Framework Convention, nor for the parties to the Kyoto Protocol. In contrast, the Parties to the CBD have regularly pointed out the link to be made between

\footnotetext{
${ }^{2}$ Watson (2005).

${ }^{3}$ See in particular IPCC (2002).

${ }^{4}$ Bellard et al. (2012).

${ }^{5}$ Secretariat of the CBD (2003).

${ }^{6}$ IPCC (2014).

${ }^{7}$ Nilsson et al. (2012).

${ }^{8} \operatorname{Kim}(2004)$.
} 
climate change and biodiversity and suggested avenues to cope with it. ${ }^{9}$

\section{Two compatible treaties}

On the one hand, the UNFCCC aims at regulating human activities causing climate change and limit their negative impacts (Preamble). On the other hand, the objectives of the CBD are the conservation of biological diversity, the sustainable use of its components and the fair and equitable sharing of the benefits arising out of the utilization of genetic resources (article 1). Obviously, their objectives are compatible if not broadly convergent and complementary.

But, despite the fact they have been negotiated simultaneously, surprisingly the two treaties do not refer explicitly, but only implicitly, to each other. The UNFCCC preamble states that the increasing of atmospheric concentrations of greenhouse gases "may adversely affect natural ecosystems and humankind". Parties declare also to be "Aware of the role and importance in terrestrial and marine ecosystems of sinks and reservoirs of greenhouse gases". UNFCCC Article 2 refers to the "stabilization of greenhouse gas concentrations in the atmosphere at a level that would prevent dangerous anthropogenic interference with the climate system. Such a level should be achieved within a time-frame sufficient to allow ecosystems to adapt naturally to climate change (...)".

The CBD preamble emphasizes "that it is vital to anticipate, prevent and attack the causes of significant reduction or loss of biological diversity at source". Similarly its Article 7 c) invite parties to "identify processes and categories of activities which have or are likely to have significant adverse impacts on the conservation and sustainable use of biological diversity, and monitor their effects (...)". Yet climate change is obviously a driver of biodiversity loss.

These implicit cross references led H. Van Asselt to conclude that fundamentally "the objectives of the UNFCCC and CBD can generally be said to be convergent". ${ }^{10}$

For its part, adopted five years later, the Kyoto Protocol does not refer to the CBD, which had been proposed by the EU but rejected by other parties. ${ }^{11}$ But its requires the COP-MOP to "assess (...) the overall effects of the measures taken pursuant to this Protocol, in particular environmental, economic and social effects as well as their cumulative impacts". 12 Moreover, each Annex I Party, in achieving its quantified emission limitation and reduction commitments, "in order to promote sustainable development, shall (...) Implement and/or further elaborate policies and measures in accordance with its national circumstances, such as (...) Protection and enhancement of sinks and reservoirs of greenhouse gases (...), taking into account its commitments under relevant international environmental agreements (...)". ${ }^{13}$

\section{COP decisions : building bridges?}

Synergies between biodiversity and climate change have been recognized within both the United Nations Framework Convention on Climate Change (UNFCCC) and the Convention on Biological Diversity (CBD). However, there seems to be less openess to address biodiversity conservation with the UNFCCC than the opposite in the CBD, where Parties have shown a particular interest in linking biodiversity and climate change related issues by adopting a number of COP Decisions which aims at improving a more integrated approach.

\subsection{Addressing climate change into the CBD}

Climate change has become progressively a key cross-cutting component of the work of the $\mathrm{CBD}$, where it has been put forward both as a threat to biodiversity and as a response

\footnotetext{
${ }^{9}$ Maes (2013).

${ }^{10}$ Van Asselt (2011).

${ }_{12}^{11}$ Morgera (2011).

${ }^{12}$ Article $13 \S 4$. See also Article $2 \S 3$ and $3 \S 14$.

${ }^{13}$ Article 2 a) ii).
} 
contributing to biodiversity conservation through mitigation and adaptation measures with biodiversity co-benefits. ${ }^{14}$ Since the year 2000, the COP of CBD adopted a myriad of decisions, looking for synergies both at the national and international levels. ${ }^{15}$ In 2001 , it formed an Ad Hoc Technical Expert Group (AHTEG) on Biodiversity and Climate Change, to consider the possible negative impacts of climate change related activities on biodiversity, identify the role of biodiversity in climate change mitigation and identify opportunities for achieving climate change and biodiversity co-benefits. The AHTEG on biodiversity and climate change has prepared several reports ${ }^{16}$, which have greatly contributed to understand what the impacts of climate change mitigation and adaptation activities are on biodiversity and how biodiversity considerations could be better integrated through the implementation of the UNFCCC and its Kyoto Protocol ${ }^{17}$.

In 2010, Parties have been encouraged to promote the importance of biodiversity considerations in REDD+ discussions ongoing in the UNFCCC negotiating process. An important Decision X/33 has been adopted at COPX, which provides for detailed guidance on possible ways to conserve, use and restore biodiversity and ecosystem services in a sustainable manner while contributing to climate change mitigation and adaptation. ${ }^{18}$ This Decision X/33 also requests its secretariat to collaborate with other international organizations to develop safeguards for biodiversity and activities implemented jointly with the other Rio Conventions. ${ }^{19}$ The same year, the COP adopted the "Aichi Biodiversity Targets", a number of which refer to climate change, including some which can directly support climate change mitigation and/or adaptation activites. It has been widely recognized that actions relating to Targets $\mathrm{n}^{\circ} 5,7,10,11,14$, and 15 are particularly relevant to address climate change and biodiversity in an interconnected manner ${ }^{20}$.

More recently, in 2012, COPXI called for a coherent and "mutually supportive" implementation of the CBD and UNFCCC ${ }^{21}$ In the context of REDD+, Parties proposed to introduce some safeguards to help developing countries reduce the potential negative impacts associated with these initiatives, including deforestation and forest degradation to areas of lower carbon value and higher biodiversity value, and their potential negative associated consequences for indigenous people and local communities. ${ }^{22}$ Calls were additionally made to highlight the significant gaps in the understanding of the impacts of climate-related geoengineering on biodiversity and the lack of science-based, global, transparent and effective legal mechanisms to control and regulate it. ${ }^{23}$

In sum, the COP to the CBD has been particularly active in addressing interactions between biodiversity conservation and climate change. Quite often, it has urged Parties to promote synergies and develop closer links with the UNFCCC and highlight the need to identify mutual actions that could be undertaken by the secretariats of the three Rio Conventions (UNFCCC, UNCCD and CBD). We could affirm that it conducted "A strategic campaign to reframe shared understandings of biodiversity from a passive victim of climate impacts to an active part of climate change solutions. ${ }^{, 24}$

\footnotetext{
${ }^{14}$ Morgera (2011).

${ }^{15}$ Ibid.

${ }^{16}$ Technical series No.10 (2003), Technical Series No. 25 (2006), Technical Series No. 41 (2009), Technical Series No. 42 (2010).

${ }^{17}$ CBD COP Decision V/4.

${ }^{18}$ Decision X/33, Biodiversity and climate change.

${ }^{19}$ Decision X/33. Para. 9 (g), para.13 (a).

${ }^{20}$ Decision X/2, The Strategic Plan for Biodiversity 2011-2020 and the Aichi Biodiversity Targets.

${ }^{21}$ Decision XI/19. See also Decision XI/21.

${ }^{22}$ Decision XI/19 Biodiversity and climate change related issues.

${ }^{23}$ Decision XI/20.

${ }^{24}$ Jinnah (2011).
} 


\subsection{Cautious openness to biodiversity in the UNFCCC}

Measures adopted to implement the UNFCCC and its Kyoto Protocol have shown that Parties have had so far little consideration of biodiversity conservation issues, with some very few exceptions in relation to forest and land use management, but always as ancillary consequences of climate mitigation or adaptation objectives.

At the Rio Summit in 2012, it was not possible to agree upon a Treaty on forest protection and management. Only a set of non-legally binding Forest Principles could be endorsed. To date, the situation is basically the same, in as far as no international agreement could be reached to cover all forests. However, as both reservoirs and sources of atmospheric carbon dioxide, forests fall also within the scope of the climate regime. Forests are both a component of, and a habitat for, terrestrial biological diversity. Accordingly, they also fall within the definition of the term biological diversity, even if the CBD makes no direct reference to forests.

Yet "While the policies and regulations being set by both regimes are largely overlapping in the area of forestry, the policy objectives of the two regimes appear to be at odds, as the evolving rules and regulations of the Kyoto Protocol are increasingly diverging from those of the CBD". ${ }^{25}$ The promotion of the enhancement of carbon sinks in the Kyoto Protocol's Clean Development Mechanism (CDM) has been a first area of concern. ${ }^{26}$ Under certain conditions, carbon sequestration some forestry project activities like afforestation and reforestation were made eligible for credits under the CDM as from 2003. But it was feared by many observers that the CDM would not protect biodiversity and prevent land degradation, on the contrary that it would provide an incentive to develop destructive but cost-effective large-scale monoculture plantations, in replacement of primary old-growth forests, thus exacerbating deforestation. ${ }^{27}$ Indeed the space given to biodiversity in secondary UNFCCC law is very limited. COP-MOP decisions are quite ambiguous and flexible, requiring only from project participants to submit to the designated operational entity some documentation on the analysis of the socio-economic and environmental impacts, including impacts on biodiversity and natural ecosystems, and impacts outside the project boundary of the proposed afforestation or reforestation project activity under the CDM. Moreover, they never refer to relevant biodiversity-related agreements like the $\mathrm{CBD} .{ }^{28}$ Certainly, Kyoto Protocol Article $2 \S 1$ a) already mentionned calls on Parties to implement policies and measures, including the protection and enhancement of sinks and reservoirs "taking into account its commitments under relevant international environmental agreements". But it doesn't specify which agreements are concerned and what means exactly "taking into account". ${ }^{29}$ As a result, "reportedly no CDM project has ever failed validation due to sustainability concerns, whereas host countries do not appear to have favored projects with so-called sustainable development co-benefits, such as improved protection of biodiversity or poverty relief ${ }^{\prime \prime} .{ }^{30} \mathrm{In}$ the end, CDM rules gave to developing countries hosting CDM forestry projects a large margin of manœuvre to impose conditions in order to protect biodiversity, in particular through the issuance of the Letter of Approval confirming that projects support the coiuntry's sustainable development objectives. But very few countries have used such prerogative.

Designed under the auspices of the UNFCCC, the REED $+{ }^{31}$ mechanism is a second area of concern. When REDD was first proposed in late 2005, many observers argued that such a

\footnotetext{
${ }^{25} \mathrm{Kim}(2004)$.

${ }^{26}$ Kyoto Protocol, Article 12. Scott (2011).

${ }^{27}$ Van Asselt (2007).

${ }^{28}$ See in Particular Decision 5/CMP.1, Modalities and procedures for afforestation and reforestation project activities under the clean development mechanism in the first commitment period of the Kyoto Protocol.

${ }^{29}$ Van Asselt (2007).

${ }^{30}$ Savaresi (2014). See also Scott (2011).

${ }^{31}$ For reducing emissions from deforestation and forest degradation.
} 
mechanism would adress both climate change mitigation, and forest biodiversity protection. ${ }^{32}$ But the impacts of REED+ on biodiversity fundamentally depend on how this mechanism is designed and implemented at national level by tropical developing countries. ${ }^{33}$ In fact, "The extent to which REDD will deliver biodiversity co-benefits depends on how and where activities are implemented. If REDD succeeds in avoiding potential negative impacts on biodiversity, it may simultaneously advance forest conservation and climate change mitigation in developping countries". ${ }^{34}$

Actually, the COP decision establishing formally the REDD+ mechanism in Cancun (2010) contained some reference to the need to respect biodiversity safeguards, though this decision did not expressly mention the CBD's guidance or role. ${ }^{35}$ The specific guidance on REDD+ safeguards and benefits which was adopted by the COP to the CBD went into much more details than that provided by the COP to the UNFCCC, enriching a "layered legal landscape". ${ }^{36}$ The proactive approach towards REDD+ within the CBD has been countered with apathy within the UNFCCC, making de facto the guidance from the CBD a key regulatory sources on biodiversity related issues for implementing REDD $+{ }^{37}$ In Warsaw (2013) where the REDD+ Handbook was to be finalized, UNFCCC Parties have recognized "the importance of incentivizing non-carbon benefits for the long-term sustainability of the implementation", which includes biodiversity conservation, though without making any reference to the CBD decisions, guidances or even objectives ${ }^{38}$. Yet, no decision has been adopted on REDD+ co-benefits, as Parties remain divided as to why and how to account for and provide support to co-benefits which are not directly climate-related.

\section{Current challenges}

\subsection{The need to improve further cooperation between the secretariats}

Article 23.4 of the CBD states that "The Conference of the Parties shall keep under review the implementation of this Convention, and, for this purpose, shall (h) Contact, through the Secretariat, the executive bodies of conventions dealing with matters covered by this Convention with a view to establishing appropriate forms of cooperation with them; and (i) Consider and undertake any additional action that may be required for the achievement of the purposes of this Convention in the light of experience gained in its operation".

For its part, Article 8.2 e) of the UNFCCC requests its secretariat to "ensure the necessary coordination with the secretariats of other relevant international bodies."

But in practice the CBD secretariat has proven to be much more dynamic, and have engaged "to a much greater extent in fostering institutional cooperation between MEAs." ${ }^{39}$ Very active, it often chairs side events and organizes press conferences in international climate change conferences ${ }^{40}$. It plays an "important and entrepreneurial role in overlap management by constructing shared understandings of why linkages matter and how they should be managed" and "overlap management appears to be an area where the Secretariat exhibits an increasing amount of cognitive influence in shaping knowledge and belief systems". ${ }^{41}$

${ }^{32}$ Wiersema (2014).

${ }^{33}$ Van Asselt (2011).

${ }^{34}$ Savaresi (2013).

${ }^{35}$ UNFCCC Decision 1/CP.16, The Cancun Agreements: Outcome of the work of the Ad Hoc Working Group on Longterm Cooperative Action under the Convention. Morgera (2011).

${ }^{36}$ A. Paterson in Maes (2013).

${ }^{37}$ Ibid.

${ }^{38}$ UNFCC Decision 9/CP.19, Work programme on results-based finance to progress the full implementation of the activities referred to in decision 1/CP.16, paragraph 70, UN doc. FCCC/CP/2013/10/Add.1, 31 Jan. 2014. See also Decision 1/CP.19, Further advancing the Durban Platform, §5. The CBD is not viewed differently from other MEAs. See UNFCCC Decision 13/CP.8, Cooperation with other conventions.

${ }^{39} \mathrm{Scott}(2011)$.

${ }^{40} \mathrm{Kim}(2014)$.

${ }^{41}$ Jinnah (2011). 
At the request of the CBD's Subsidiary Body for Scientific, Technical and Technological Advice, a Joint Liaison Group (JLG) between the three Rio Conventions was established in 2001 , comprising the officers of the subsidiary bodies, the executive secretaries of the three conventions and members of the secretariats. Originally, it was designed as an informal forum for exchanging information, exploring opportunities for synergistic activities and increasing coordination among the three conventions and their secretariats, for the benefit of their respective Parties. Each of the COP of the three conventions has encouraged the JLG to facilitate cooperation at the national and international levels, to identify possible areas of joint activities, and to enhance coordination ${ }^{42}$. The JLG had been convened nine times, focusing on cross-cutting points as research and monitoring, information exchange, technology transfer, capacity building, financial resources, and adaptation to climate change. For example, the Joint Liaison Group highlighted that, work may be explored on the links between National Biodiversity Strategy and Action Plans (NBSAPs) and National Adaptation Program Plan (NAPAs) under the UNFCCC.

But the JLG faces a number of obstacles. Its functioning is institutionally and financially constrained ${ }^{43}$. In 2009, the JLG noted that "there remains a disconnect between the roles and mandates given to the JLG by each convention with this disconnect resulting in limitations when considering the implementation of the requested activities. For example, only activities that are mandated by all the governing bodies of each convention could be effectively implemented by the JLG". ${ }^{44}$ The work of the JLG can also be limited due to State reluctance or even political opposition to a defragmentation of these regimes. For instance, the United States is a Party to the UNFCCC but neither to the CBD nor to the Kyoto Protocol. In the end, the JLG has had a very limited impact on integrating issue areas. ${ }^{45}$

In addition to the coordination done through the JLG, the secretariats attend each other's meetings and organise joint workshops to address synergies between the treaties. ${ }^{46}$ However as it has been noticed, it is obvious that clustering efforts so far have focused on the biodiversity-related conventions rather than the climate change conventions, while there has been very little attention to clustering efforts between the two clusters. ${ }^{47}$ Regarding the UNEP, its mandate originally include the coordination of environmental activities in the UN system. ${ }^{48}$ According to Harro van Asselt "A key problem in the climate-biodiversity case is that the UNFCC is not formally linked to UNEP. Without an agreed formal relationship between the climate and biodiversity regimes, it is difficult to see how UNEP could coordinate the relationship between the climate and biodiversity regimes. "49 Between the UNEP and UNFCCC, institutionally UNEP is dwarfed. By consequence, its role is not really relevant.

\subsection{Improving common understanding and cognitive and normative consistency}

An improved understanding could come first from the development of expertise and scientific linkages. Article 25 of the CBD and Article 9 of the UNFCCC respectively provides for the establishment of a Subsidiary Body for Scientific and Technological advice (SBST(T)A). Unsurprisingly, guided by CBD COP decisions, the CBD SBSTTA has been more active to stimulate the interface between climate and biodiversity related issues than that of the UNFCCC. But the work of these two scientific bodies is too compartmentalized to

\footnotetext{
${ }^{42}$ CBD decision VI/20, CCD decision 12/COP.6, FCCC decision 13/CP.8.

${ }^{43}$ Scott (2011).

${ }^{44}$ Joint Liaison Group of the CBD, the UNCCD, and the UNFCCC, Ninth meeting, New York, 14 May 2009, Report of the Meeting of the JLG of the CBD, p. 3.

${ }^{45} \operatorname{Scott}(2011)$.

${ }^{46}$ Van Asselt (2007).

${ }^{47}$ Maes (2013).

${ }^{48}$ Resolution 2997 (XXVII) of 15 December 1972.

${ }^{49}$ Van Asselt (2014).
} 
allow taking into account the complexity of the environment and its interactions. We agree with Morin and al. that one promising avenue for approaching interactions within regime complexes is through "knowledge management" ${ }^{50}$ From this viewpoint, the IPCC delivered several reports on biodiversity and climate, but without clear connections with the CBD provisions $^{51}$. The International Platform on Biodiversity and Ecosystem Services (IPBES) could however play a more important role in bridging the gap between the two conventions, by addressing the interface management of biodiversity and climate related isues. It can be boosted by the circulation of IPBES stakeholders between biodiversity and climate "regime complexes" $^{\prime \prime 2}$. Yet clearly connected with convention' bodies, it has a great potential to impact policymaking. Some reconciliation between IPCC and IPBES would also be welcome and this seems to take off. In October 2014, IPCC stated that "it was seen as important to continue and further enhance cooperation with other UN bodies, especially UNFCCC, and assessment processes such as IPBES, through the IPCC Secretariat."53 At the Third meeting of the IPBES in January 2015, Rajendra Pachauri, who was still the IPCC Chair, suggested that the respective IPCC and IPBES "Bureau" should meet periodically to explore matters of substance in their respective assessments. ${ }^{54}$

Additionnally, some concepts or principles seem to bring new synergies between the climate and biodiversity. The Aichi Targets or furthermore the overarching Sustainable Development Goals to be adopted in September 2015 have this potential. Developing commonalities between regimes through common principles or strategic objectives help to prevent conflict between multilateral environmental agreements. ${ }^{55} \mathrm{New}$ concepts or tools could play a role, like the emerging concept of ecosystem services in the future as it is not yet fully matured and conveys controversial synergies. ${ }^{56}$ At the end one could add that "international law, and in particular the emerging concept of systemic integration, has the potential to make a positive contribution to the climate-trade interplay". ${ }^{57}$

\subsection{Improving consistency through fundings?}

At first, synergies were expected from the way the Global Environment Facility (GEF) would support climate and biodiversity protection projects or activities in as far as the GEF has been for quite a long period the only entity in charge of the financial mechanism of both the CBD and the UNFCCC ${ }^{58}$ All the more that actually $21 \%$ of GEF projects can be regarded as cross-sectoral/issued. ${ }^{59}$ But the GEF spending for biodiversity projects or activities is very limited when compared with the amount of climate finance that developed countries' Parties have committed to mobilise in Copenhagen, e.g 100 billion $\$$ year by 2020, a large portion of which should be spent through the Green Climate Fund formally established in Cancun in 2010, which is expected to be fully operational this year with a first call for projects announced before COP21. The Green Climate Fund is in a very good position to promote win-win projects or activities between the fight against climate change and biodiversity protection, including through joint mitigation and adaptation projects that would also have positive effects on the fight against desertification in arid and semi-arid regions.

\footnotetext{
${ }^{50}$ Morin et al. (forthcoming).

${ }^{51}$ IPCC $(1991,2000,2002)$.

${ }^{52}$ Hrabanski and Oubenal (forthcoming).

${ }^{53}$ IPCC (2014) (2).

${ }^{54}$ See also the "Lima 2014 Declaration on Biodiversity and Climate Change. From Science to Policy", adopted on the margins of the UNFCCC COP 20.

${ }^{55}$ Sindico and al. (2008).

${ }^{56}$ Maes (2011).

${ }^{57}$ Van Asselt et al. (2008).

${ }^{58} \mathrm{Kim}(2004)$.

${ }^{59}$ UNFCCC (2014).
} 
This is all the more important to think through such an integrated approach that financial support available for CBD activities and projects are obviously not enough to meet the Aichi Targets.$^{60}$ There is thus a real challenge to develop a "holistic approach ${ }^{61 \text { " }}$ requiring also a financial cooperation between UN agencies, World Bank acting as a Trustee or in its capacity, and the three Rio Conventions.

\subsection{Challenges and future perspectives of the climate Paris agreement}

Parties should be inspired by an integrated approach for the elaboration of their Intended Nationally Determined Contributions (INDCs), which will constitute an esssential part of UNFCCC Parties' efforts and actions to be anchored in the agreement to be reached in Paris at COP21 in December 2015. Parties may decide on a voluntary basis to include an adaptation component in their INDCs. It is worth notice that on 12 February 2015, the CBD Secretariat has published a notification compiling existing tools, guidance and information related to biodiversity and climate change, and has encouraged CBD Parties to use it for the development of their Intended Nationally Determined Contributions to be communicated in the context of the development of the climate agreement to be reached in Paris. ${ }^{62}$

In the preambular part of the agreement to be reached in Paris at the COP2 1 of the UNFCCC, coherence and synergies between the three Rio Conventions at both international and national levels should be called upon in a clear and straightforward manner. This call for such a mainstreaming exercise could be reflected in the principles laying down the foundations of the future international climate regime through a clause stating clearly the principle that implementation of each of the Rio Convention should be done in a mutually supportive manner with the two others. ${ }^{63}$ Combined with a no backsliding principle in climate change policies, this mutual support would have a domino effect on biodiversity conservation and the fight against desertification. This Paris agreement may refer to the UNFCCC provisions addressing ecosystems and natural habitats, including oceans which are part of the hydrosphere, so as to ensure that such agreement builds upon and strengthen the acquis.

In addition, biodiversity concerns or objectives should be fully taken into consideration through the procedures and modalities that will have to be adopted for implementing INDCs, measuring progress made by Parties and reviewing their adequacy in terms of ambition and consistency over time.

One could not ignore the resistance of some parties to improve connections between the two regimes. They originate in both the fear to pollute CBD discussions importing UNFCC difficulties and blocages and the feeling of losing sovereignty by importing concepts or rules from the $\mathrm{CBD}^{64}$ in particular knowing that important States like the United States are not parties to the CBD.

\section{Conclusion}

In recent years, and despite the efforts of the CBD, the issue of biodiversity has in most cases been overshadowed by the issue of human-induced climate change, yet both are equally important, if not fundamental to the ongoing future of human populations and even planetary life. Indeed these two issues are closely connected and this should be reflected in policies and legal tools ${ }^{65}$. As shown by the lack of cross-reference in decisions taken in the context of the international climate change regime, the UNFCCC behaves sometimes like an autistic convention hermetic to external concerns. According to some authors, "the connection with

\footnotetext{
${ }^{60}$ Morgera (2011).

${ }^{61}$ Boisson de Chazournes (2002-2003).

${ }^{62} \mathrm{SCBD} / \mathrm{SAM} / \mathrm{DC} / \mathrm{SK} / \mathrm{AC} / 84278$.

${ }^{63}$ In the same way, to go further than CBD Article 22§1, see Chambers (2008).

${ }^{64}$ Wolfrum and Matz (2003).

${ }^{65}$ Jóhannsdóttir et al. (2010).
} 
issues other than its own has been seen as an unwanted distraction to achieving its narrowly defined and interpreted object and purpose". ${ }^{66}$ In fact, it is a matter of effectiveness. COP 21 provides an opportunity to make a decisive step toward a better open approach of other issues and regimes. In the same time, scholars have to pay more attention for the coming years both to interplays between the climate regime and other pieces of the biodiversity regime complexe ${ }^{67}$ but also to the management of regime complexity at the national level. ${ }^{68}$

${ }^{66}$ Chambers (2008).

${ }^{67}$ For example the CMS Convention or the Ramsar Convention, or even regional conventions. See Trouwborst (2012).

${ }^{68}$ Gomar et al. (2014). 


\section{Bibliography}

- C. Bellard, C. Bertelsmeier, P. Leadley,W. Thuiller, F. Courchamp, 'Impacts of climate change on the future of biodiversity'(2012) 15 Ecology Letters 365

- F. Biermann, 'Planetary boundaries and earth system governance: exploring the links' (2012) 81 Ecological Economics 4

- F. Biermann, P. Pattberg, H. Van Asselt, 'The Fragmentation of Global Governance Architectures: A Framework for Analysis' (2009) 9 Global Environmental Politics 14

- L. Boisson de Chazournes, 'The global environment facility (GEF) as a pioneering institution' (2002-2003) 77 Philippine Law Journal 11

- W. Boyd, 'Ways of Seeing in Environmental Law: How Deforestation Became an Object of Climate Governance' (2010) 37 Ecology Law Quarterly 843

- M. Buizer, D. Humphreys, W. de Jong, 'Climate change and deforestation: the evolution of an intersecting policy domain', (2014) 35 Environmental Science and Policy 1

- W. B. Chambers, Interlinkages and the Effectiveness of Multilateral Environmental Agreements (United Nations University Press 2008) 252

- M. Daccache, 'Questioning Biodiversity Governance through Its Articulations' (2013) 18 Science Technology \& Society 51

- F. Danielsen et al., 'Biofuel Plantations on Forested Lands: Double Jeopardy for Biodiversity and Climate' (2008) 23(2) Conservation Biology 348

- M. Doelle, 'Linking the Kyoto Protocol and Other Multilateral Environmental Agreements: From Fragmentation to Integration?' (2004) 14 Journal of Environmental Law and Practice 75

- J.E. Hecht, B. Orlando, 'Dialogues: can the Kyoto Protocol support biodiversity conservation? legal and financial challenges' (2000) 98 The Environmental Law Reporter 10508

- M. Hrabanski, M. Oubenal, 'The Circulation of IPBES Stakeholders between Biodiversity and Climate Regime Complexes' (forthcoming)

- IPCC, Assessment of the Vulnerability of Coastal Areas to Sea Level Rise. A Common Methodology (IPCC 1991)

- IPCC, A Special Report on Land Use, Land-Use Change and Forestry: Summary for Policy Makers (Cambridge University Press 2000)

- IPCC, Climate change and biodiversity, Technical paper V (IPCC 2002)

- IPCC, 'Summary for Policymaker's' in Climate Change 2014: Mitigation of Climate Change. Contribution of Working Group III to the Fifth Assessment Report of the Intergovernmental Panel on Climate Change (Cambridge University Press, 2014)

- IPCC (2014 2), Future work of the IPCC. Further refined Options Paper resulting from the discussions at the Third meeting of the Task Group on the Future Work of the IPCC, Fortieth Session of the IPCC, Copenhagen, Denmark, 27-31 October 2014, IPCC-XL/Doc.13, Add.1 (30.X.2014).

- F. Jacquemont, A. Caparrós, 'The Convention on Biological Diversity and the Climate Change Convention 10 Years After Rio: Towards a Synergy of the Two Regimes?' (2002) 11 Review of European Community and International Environmental Law 139

- S. Jinnah, 'Marketing Linkages: Secretariat Governance of the Climate-Biodiversity Interface' (2011) 11 Global Environmental Politics 23

- A. Johannsdottir, I. Cresswell, P. Bridgewater, 'The current framework for international governance of biodiversity: Is it doing more harm than good?' (2010) 19 Review of European Community and International Environmental Law 139

- J. A. Kim, 'Regime interplay: The case of biodiversity and climate change' (2004) 14 
Global Environmental Change 315

- R. E. Kim, 'Is a new multilateral environmental agreement on ocean acidification necessary?' (2012) 21 Review of European Community and International Environmental Law, 243

- Ph. Le Prestre, Governing Global Biodiversity, The Evolution and Implementation of the Convention on Biological Diversity (Ashgate 2002) 448

- H. Locke, B. Mackey, 'The nature of climate change: Reunite international climate change mitigation efforts with biodiversity conservation and wilderness protection' (2009) 15 International Journal of Wilderness 7

- F. Maes et al (eds), Biodiversity and Climate Change: Linkages at International, National and Local Levels (Edward Elgar 2013) 460

- E. Morgera, 'No Need to Reinvent the Wheel for a Human Rights-based Approach to Tackling Climate Change: The Contribution of International Biodiversity Law' in Hollo, Kulovesi, and Mehling, Climate Change and the Law (Springer 2013) 359

- E. Morgera, 'Faraway, So Close: A Legal Analysis of the Increasing Interactions between the Convention on Biological Diversity and Climate Change Law' (2011) 2 Climate Law 85

- J.-F. Morin, A. Orsini, 'Regime Complexity and Policy Coherency: Introducing a Coadjustments Model' (2013) 19 Global Governance 41

- J.-F. Morin, S. Louafi, A. Orsini, M. Oubenal, 'Boundary Organizations in Regime Complexes: A Social Network Assessment of IPBES' (forthcoming)

- M. Nilsson, Å. Persson, 'Reprint of 'Can Earth system interactions be governed? Governance functions for linking climate change mitigation with land use, freshwater and biodiversity protection" (2012) 81 Ecological Economics 10

- S. Oberthür, 'Interplay Management: Enhancing Environmental Policy Integration Among International Institutions' (2009) 9 International Environmental Agreements: Politics, Law and Economics 371

- S. Oberthur, 'Clustering of multilateral environmental agreements: Potentials and limitations' (2002) 2 International Environmental Agreements: Politics, Law and Economics, 317

- A. Orsini, J.-F. Morin, O. Young, 'Regime Complexes: A Buzz, a Boom, or a Boost for Global Governance?’ (2013) 19 Global Governance 27

- J. Paavola, A. Gouldson, T. Kluvánková-Oravská, 'Interplay of Actors, Scales, Frameworks and Regimes in the Governance of Biodiversity' (2009) 19 Environmental Policy and Governance 148

- G. K. Rosendal, 'Impacts of Overlapping International Regimes: The Case of Biodiversity’ (2001) 7 Global Governance 95

- G. K. Rosendal, 'Overlapping International Regimes. The Case of the Intergovernmental Forum on Forests (IFF) between Climate Change and Biodiversity' (2001) 1 International Environmental Agreements: Politics, Law and Economics 447

- I. Sagemüller, 'Forest Sinks under the United Nations Framework Convention on Climate Change and the Kyoto Protocol: Opportunity or Risk for Biodiversity?' (2006) 31 Columbia Journal of Environmental Law p. 189

- A. Savaresi, 'Reducing Emissions from Deforestation in Developing Countries under the United Nations Framework Convention on Climate Change. A New Opportunity for Promoting Forest Conservation?' in F. Maes et al (eds), Biodiversity and Climate Change: Linkages at International, National and Local Levels (Edward Elgar 2013) 237

- A. Savaresi, 'The emergence of benefit-sharing under the climate regime. A preliminary exploration and research agenda' (2014) 4 Working Paper for the 


\section{BENELEX Project}

- K. Scott, 'International environmental governance : managing fragmentation through institutional connection' (2011) 12 Melbourne Journal of International Law 1

- Secretariat of the Convention on Biological Diversity (SCBD), Connecting Biodiversity and Climate Change Mitigation and Adaptation: Report of the Second Ad Hoc Technical Expert Group on Biodiversity and Climate Change (SCBD 2009)

- Secretariat of the Convention on Biological Diversity (SCBD) Interlinkages Between Biological Diversity and Climate Change. Advice on the Integration of Biodiversity Considerations into the Implementation of the United Nations Framework Convention on Climate Change and its Kyoto Protocol (SCBD, 2003)

- O. S. Stokke, S. Oberthür, 'Introduction: Institutional Interaction in Global Environmental Change' in S. Oberthür and O.S. Stokke (eds) Managing Institutional Complexity: Regime Interplay and Global Environmental Change (MIT Press 2011) 1

- A. Trouwborst, 'Transboundary Wildlife Conservation in A Changing Climate: Adaptation of the Bonn Convention on Migratory Species and Its Daughter Instruments to Climate Change' (2012) 4 Diversity 258

- A. Trouwborst, 'Conserving European Biodiversity in a Changing Climate: The Bern Convention, the European Union Birds and Habitats Directives and the Adaptation of Nature to Climate Change' (2011) 20 Review of European Community \& International Environmental Law 62

- UNFCCC, Guidance from the conference of the Parties and responses by the Global environment facility 20 Years (UNFCCC 2014)

- H. Van Asselt, 'Dealing with the Fragmentation of Global Climate Governance. Legal and Political Approaches in Interplay Management' (2007) 30 Global Governance Working Paper http://www.glogov.org/images/doc/WP30.pdf

- H. Van Asselt, F. Sindico, M. A. Mehking, 'Global Climate Change and the Fragmentation of International Law' (2008) Law and Policy 423

- H. Van Asselt, 'Integrating Biodiversity in the Climate Regime's Forest Rules: Options and Tradeoffs in Greening REDD Design' (2011) 20 RECIEL 139

- H. Van Asselt, 'Managing the fragmentation of international environmental law: Forests at the intersection of the climate and biodiversity regimes' (2012) $44 \mathrm{New}$ York University Journal of International Law and Politics 1205

- H. Van Asselt, The Fragmentation of Global Climate Governance: Consequences and Management of Regime Interactions (Edward Elgar Pub. 2014) 224

- J.O. Velázquez Gomar, L.C. Stringer, J. Paavola, 'Regime Complexes and National Policy Coherence: Experiences in the Biodiversity Cluster' (2014) 20 Global Governance 119

- R. Watson et al, Ecosystem and human well-being. Synthesis (UNEP 2005)

- A. Wiersema, 'Climate Change, Forests, and International Law: REDD's Descent into Irrelevance' (2014) 47 Vanderbilt Journal of Transnational Law 1

- M. A. Young, 'Climate Change Law and Regime Interaction' (2011) 21 CCLR 147 